\title{
P02.15. Acupuncture improves in vitro fertilization live birth outcomes: a retrospective chart review
}

\author{
L Hullender Rubin $^{1 *}$, M Opsahll$^{2}$, D Ackerman ${ }^{1}$ \\ From International Research Congress on Integrative Medicine and Health 2012 \\ Portland, Oregon, USA. 15-18 May 2012
}

\section{Purpose}

The effectiveness of adjuvant acupuncture on the day of embryo transfer (ET) to improve in vitro fertilization (IVF) outcomes is unclear. Most trials thus far have shown some or no effect. In this retrospective chart review, we investigated if a unique acupuncture protocol had any effect on IVF live births.

\section{Methods}

From 2008-2009, patients at a private infertility clinic in Kirkland, WA could elect onsite adjuvant acupuncture on the day of ET. Of 464 patients who received ET, 188 elected acupuncture (Acu) and $276 \operatorname{did}$ not (No Acu). The Acu group received two standardized acupuncture treatments. Prior to ET, the following points were needled: GV20, PC6, ST29, SP8, LV3 and R6 with Shenmen and Brain on the left ear and Uterus and Endocrine on the right ear. Post ET, the same points on opposite ears and LI4, SP10, ST36, and SP6 were needled. Live birth outcomes were analyzed using logistic regression with age and follicle stimulating hormone (FSH) as covariates. Differences across categories of maternal age were evaluated with crude risk ratios.

\section{Results}

There were 106 (56\%) live births in the Acu group and 126 (35\%) in the No Acu group (OR=1.68, CI=1.14-2.46, $\mathrm{p}<0.001)$. Live births associated with acupuncture were significantly higher in the 35-37 age group $(R R=1.86$, $\mathrm{CI}=1.18-2.94, \mathrm{p}=0.01)$ and the $38-40$ age group $(\mathrm{RR}=1.79, \mathrm{CI}=1.02-3.15, \mathrm{p}=0.04)$. In the under 35 and over 40 age groups, there were somewhat more live births in the Acu groups although the differences did not reach statistical significance.

10regon College of Oriental Medicine, Research Department, Portland, USA Full list of author information is available at the end of the article

\section{Conclusion}

IVF live birth outcomes may be improved with this unique acupuncture protocol. This finding should be taken cautiously as more rigorous research is needed.

\section{Author details \\ 'Oregon College of Oriental Medicine, Research Department, Portland, USA. \\ ${ }^{2}$ Northwest Center for Reproductive Medicine, Kirkland, USA.}

Published: 12 June 2012

doi:10.1186/1472-6882-12-S1-P71

Cite this article as: Rubin et al:: P02.15. Acupuncture improves in vitro

fertilization live birth outcomes: a retrospective chart review. BMC

Complementary and Alternative Medicine 2012 12(Suppl 1):P71.
Submit your next manuscript to BioMed Central and take full advantage of:

- Convenient online submission

- Thorough peer review

- No space constraints or color figure charges

- Immediate publication on acceptance

- Inclusion in PubMed, CAS, Scopus and Google Scholar

- Research which is freely available for redistribution

Submit your manuscript at www.biomedcentral.com/submit
() Biomed Central

\section{() BioMed Central}

